\title{
Hybrid Resource Environmental Value Chain Model Based on a Discrete Time Algorithm
}

\author{
Wenting Cao $\mathbb{D}^{1},{ }^{1}$ Melkamu Teshome Ayana $\mathbb{D}^{2},{ }^{2}$ and Rongwei Gao $\mathbb{D}^{3}$ \\ ${ }^{1}$ School of Economics and Management, Fuzhou University, Fuzhou 350108, China \\ ${ }^{2}$ Department of Hydraulic and Water Resources Engineering, Arba Minch University, Ethiopia \\ ${ }^{3}$ Planning and Design Institute 1, Fujian Provincial Institute of Architectural Design and Research Co. Ltd., Fuzhou 350001, China
}

Correspondence should be addressed to Melkamu Teshome Ayana; melkamu.teshome@amu.edu.et

Received 27 March 2021; Accepted 29 May 2021; Published 15 June 2021

Academic Editor: Vimal Shanmuganathan

Copyright (c) 2021 Wenting Cao et al. This is an open access article distributed under the Creative Commons Attribution License, which permits unrestricted use, distribution, and reproduction in any medium, provided the original work is properly cited.

Due to the inconsistency between resource environment and value data types, the hybrid model of resource environment value chain cannot effectively coordinate the relationship among resources, environment, and value chain. The circulation of resource chain, ecological chain, and value chain is not completed independently; they are intertwined and promote each other. Therefore, this paper proposes a hybrid resource environmental value chain model based on a discrete time algorithm. Analyze the hybrid internal structure of resource chain, environment chain, and value chain model; integrate the natural resource information through the objective function of natural resource integration; obtain the indicators affecting the environment; and complete the analysis of the characteristics of environmental change. On this basis, the relationship between resources, environment, and economic value is analyzed, and the hybrid content of resources, environment, and value chain is determined. The discrete-time algorithm is introduced to transform the hybrid content into the same data format, obtain the objective function and constraints of the resource environment value chain hybrid model, and complete the construction of the resource environment value chain hybrid model based on the discrete-time algorithm. The simulation results show that the hybrid model designed in this paper can effectively improve the resource saving rate, up to $97 \%$, and the error of resource environment value chain data fusion is the lowest, and the time is less than 1 min which was a considerable achievement.

\section{Introduction}

Since the 1990s, the problems of resources and environmental protection have become a hot topic in manufacturing industry, and the concept of green manufacturing has been put forward. This is a modern enterprise production mode based on environmental protection competition strategy. Mechanical engineering scholars mostly discuss the general theoretical system, special technology, and other aspects of green manufacturing, involving the concept and content of green design to a certain extent, mainly from the aspect of manufacturing technology, but these studies only examine the technical greenness of products and their manufacturing design schemes, which is not enough, and need further costbenefit analysis [1]. In recent years, most of the production industries have formed an industrial model of "raw materials production processing sales." Among them, raw materials are mainly obtained from the natural environment, are produced into products through generation and processing technology, and obtained economic benefits through sales to achieve industrial value. Resources are all kinds of material elements such as material resources, financial resources, and human resources in a country or a certain area. It can be divided into natural resources and social resources. The environment includes not only the material factors including atmosphere, water, soil, plants, animals, and microorganisms but also the nonmaterial factors including ideas, systems, and codes of conduct; not only the natural factors but also the social factors; and not only the nonlife forms but also the life forms. The conditions for the existence and development of an industrial enterprise must create value for its shareholders and other interest groups. The process of creating value is divided into a series of different but interrelated economic activities, or "value-added activities," which constitute the 
enterprise "value chain" [2]. In the process of enterprise operation, we pay more attention to the economic benefits of the enterprise and ignore the environmental protection and the rational use of resources, so there are environmental pollution, resource shortage, and other problems. In order to solve this problem, researchers in this field have done a lot of research.

The hybrid model of resource environment value chain enables enterprises to pay attention to the value of products and the benefits of enterprises in operation and production, realize the rational use of resources, and minimize the damage to the natural environment. By nesting the three parts of resources, environment, and value chain, a coordinated and linked mechanism is formed, so as to balance the industrial economy and resource environment and the relationship between. Foreign research on the hybrid development of resource environment value chain mainly focuses on the development of environmental industry in developed countries, the driving force of industrial development, and the necessity of environmental industry development [3].

The literature [4] proposes a multilevel hybrid model based on resources, ecology, and value chain industrial circular economy system. Based on the idea of symbiotic circular economy, through literature review, theoretical analysis, practical research, and expert consultation, according to the logic of resource chain, ecological chain, and value chain, this model studies the ecological environment subsystem in a wider range, The core structure model of circular economy and its multilevel extended structure model of social economic subsystem can effectively reduce environmental pollution, but its analysis process is complex and time-consuming, which cannot be applied in practice. In reference [5], a zero model for hybrid decision of resource environment symbiotic network is proposed. The construction of the model is an important basis to determine the network nesting. By exploring the influence of matrix asymmetry on the network nesting based on different zero model construction methods, this paper attempts to provide a basis for the selection of the zero model of asymmetric network. The construction of the model can effectively reduce the deviation error of pairing overlap degree and improve the accuracy. However, the sensitivity of the model is insufficient in determining the nesting of highly asymmetric networks, and there are obvious problems of resource, environment, and value chain inconsistency.

In order to solve the problems in the traditional hybrid model of resource environment value chain, a discrete time algorithm is introduced. The discrete-time algorithm can consider the running time and cost of enterprise project comprehensively, which is more in line with the multiobjective characteristics of a hybrid model. Based on the traditional hybrid model of resource environment value chain, the discrete-time algorithm is used to deal with the three components of the model, and the hybrid structure is replanned to achieve the optimal design of the hybrid model. Coordinate resources, environment, and value chain in the same position in operation, and realize the protection of environmental resources on the basis of ensuring enterprise value and benefit.

\section{Design of Hybrid Model of Resource Environment Value Chain}

Ecological economy requires people to use ecological laws to guide human economic activities, reconstruct the economic system according to the laws of material circulation and energy flow of the natural ecosystem, integrate the economic system into the material circulation process of the natural ecosystem, and integrate clean production, comprehensive utilization of resources, ecosystem construction, sustainable consumption, and interest balance. Therefore, the economic model is a kind of economic development model to promote the coordination and harmony between human and nature. The economic system of most enterprises' production industry chain itself spans the economic system and natural system and has the unique structure and green symbiosis characteristics that the general economy is not prepared for. The implementation process of enterprise production industry chain is shown in Figure 1.

Among them, the main driving factors of industrial development in the mature stage are economic stimulus, public environmental awareness, and corporate social responsibility. In the mature stage of the industry, due to the gradual improvement of environmental laws and regulations, the improvement of public environmental awareness, the improvement of the ability of enterprises to bear environmental responsibility, and the reduction of the role of environmental laws and regulations help in promoting the environmental industry [6]. Through the application of the hybrid model of resource environment value chain and the assistance of relevant laws and regulations, the balance of resource, environment, and enterprise value can be realized.

\subsection{Hybrid Structure Analysis of Resource Environment} Value Chain. A hybrid model is a kind of structural equation model. If all free parameters of a model are part of the same parameters in model $\mathrm{B}$, a model is said to be hybrid in the model [7]. In the path graph, the path graph of model A can be obtained by removing some paths from the path graph of model B. Combined with the basic structure of the hybrid model, the planning of the hybrid model structure of resource environment value chain is realized from three aspects: resource chain, ecological environment chain, and value chain.

2.1.1. Hybrid Structure of Resource Chain. In the upstream of the resource chain, the extended structure model regards resource cultivation as the "first workshop" of product production, providing stable raw material source with low transaction cost and operation risk for the product production and processing process; the external market transaction channel with high transaction cost, high risk, and poor stability of the supply chain is only used as an auxiliary raw material source. In order to improve the utilization rate of natural resources, the natural raw material sources of the product industry also include "three residues," i.e., cutting residues, wood making residues, and processing residues [8]. The production enterprise and its supply chain members invest in the raw material base to form a forest management cycle. 


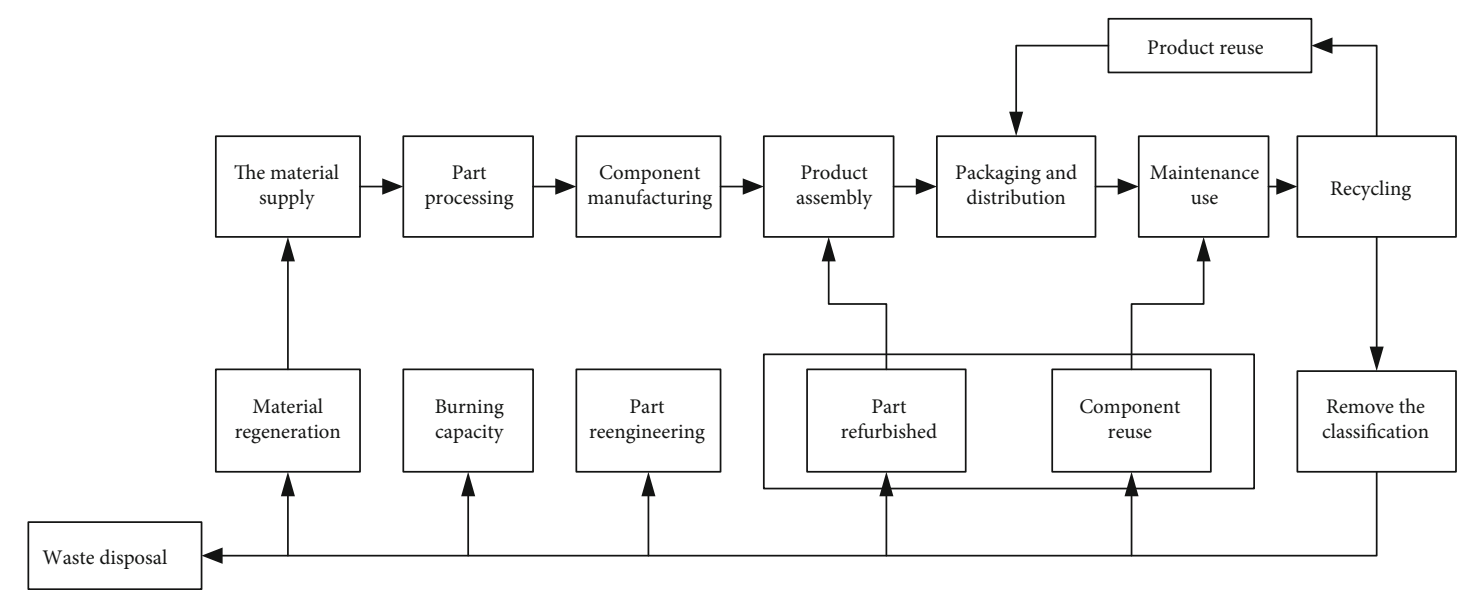

FIGURE 1: Flow chart of enterprise production industry chain.

In the downstream of the resource chain, the economic system can be extended to the recycling of waste in the consumption link, that is, reverse logistics industry or vein industry. The expanding fields mainly include chemical processing cycle and wood physical processing cycle. In the circulation chain, raw materials are used in a certain step of the technological process, and products are formed through a series of complex chemical processing processes for consumers to use. Then, the consumer's waste products after use are recycled and treated properly as product processing raw materials for recycling [9]. From the perspective of resource chain, economic system can be hybrid in product processing industry and comprehensive utilization of production process waste.

2.1.2. Hybrid Structure of Environment Chain. The structure of resource chain expansion provides the necessary biological basis for the further expansion of the enterprise economic system to the ecological environment subsystem. On this basis, according to the operation principle of ecosystem, the environment chain expansion structure of enterprise economic system is constructed, as shown in Figure 2.

In Figure 2, the environment chain is hybrid as a grey box of "CE resource chain extension structure," in which the directed solid line is the main resource chain. Outside the grey box, each box represents the process of promoting the healthy development of the ecosystem, which is called "ecological process" for short; connecting each box with the directional dotted line represents the ecological flow, which is called "ecological force" for short. Different from resource flow, ecological flow has gone beyond the scope of material flow and energy flow. It forms ecological forces through material flow, energy flow, capital flow, technology flow, process flow, and other "fluids." In this paper, the environmental chain is composed of ecological process and ecological flow.

In product manufacturing and its horizontal expansion of supply chain enterprises, ecological chain circulation is formed through the ways: first, under the guidance of resource processing integration strategy, industrial raw material construction is carried out to solve the problem of enterprise raw material supply on the one hand and make contribution to the construction of natural ecosystem on the other hand $[10,11]$. Under the guidance of green marketing strategy, carry out a forest certification work and implement sustainable management of natural resources. After the treatment of processing wastewater, after removing harmful substances, there are rich organic substances left, which can be used to irrigate natural resources, which is conducive to the growth and construction of natural resources. In addition, sludge and separated elements are rich in organic matter, N, P, K, and other substances that are conducive to the growth of natural resources, which can be used to develop special compound fertilizers and soil improvers for quick natural resources.

If we want to make the environment have good ecological benefits, the process not only should have good ecological functions but also depends on the input ecological power. The positive direction of ecological input will play a role in promoting ecological benefits, while the negative direction will play a role in destroying the ecology. Therefore, only through the virtuous cycle of the whole ecological chain system can we finally achieve the management objectives of ecological construction and environmental protection.

2.1.3. Hybrid Structure of Value Chain. Using the same structure as the environment chain, the environment chain structure is hybrid into the value chain structure. In value chain planning, the optimization and coordination of supply chain benefit distribution are an important part of value chain and a process of supply chain management. Reasonable benefit distribution can mobilize the enthusiasm of each subject of circular economy, and then a series of benign cycle processes will take place: promoting the coordination and effective operation of value chain itself, encouraging the economic subject of relevant enterprises, making continuous input to the cultivation of natural resources, realizing value feedback, and then promoting the benign cycle of resource chain and environmental chain of economic system and the health of resource chain and environmental chain In turn, healthy development supports the healthy growth of the value chain and ultimately promotes the sustainable development of the entire economic system [12]. 


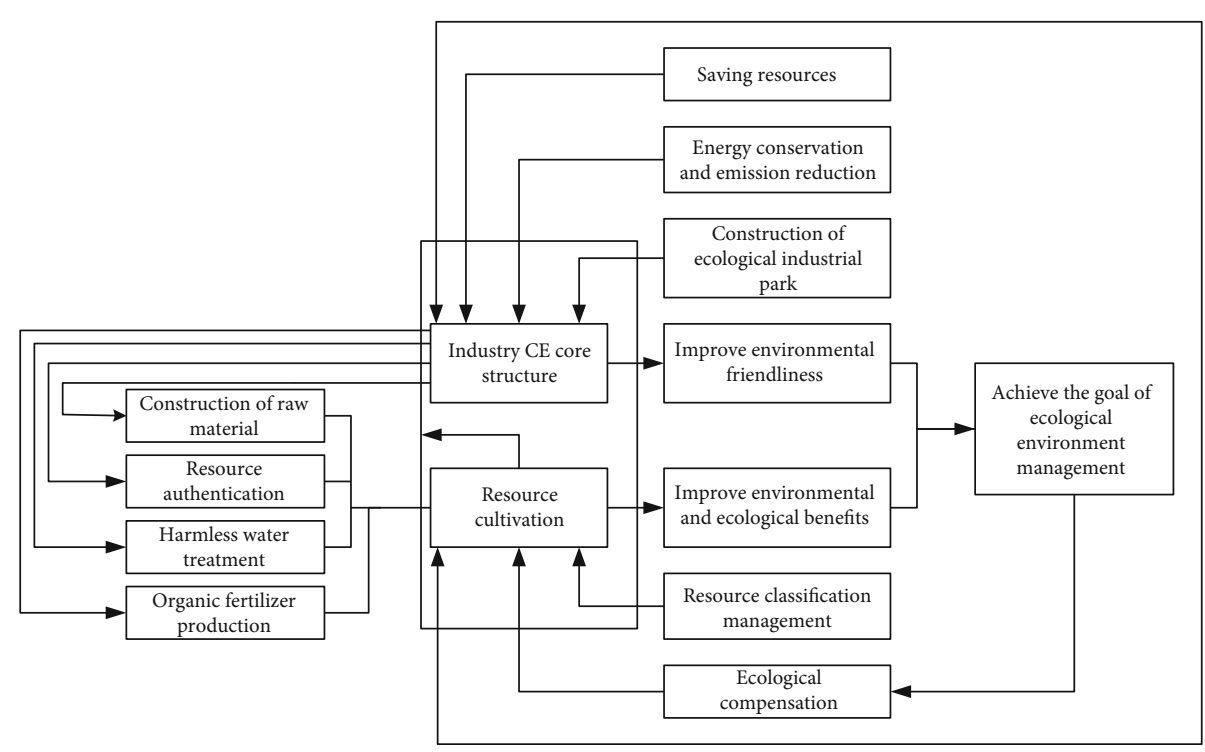

FIGURE 2: Hybrid structure of environment chain.

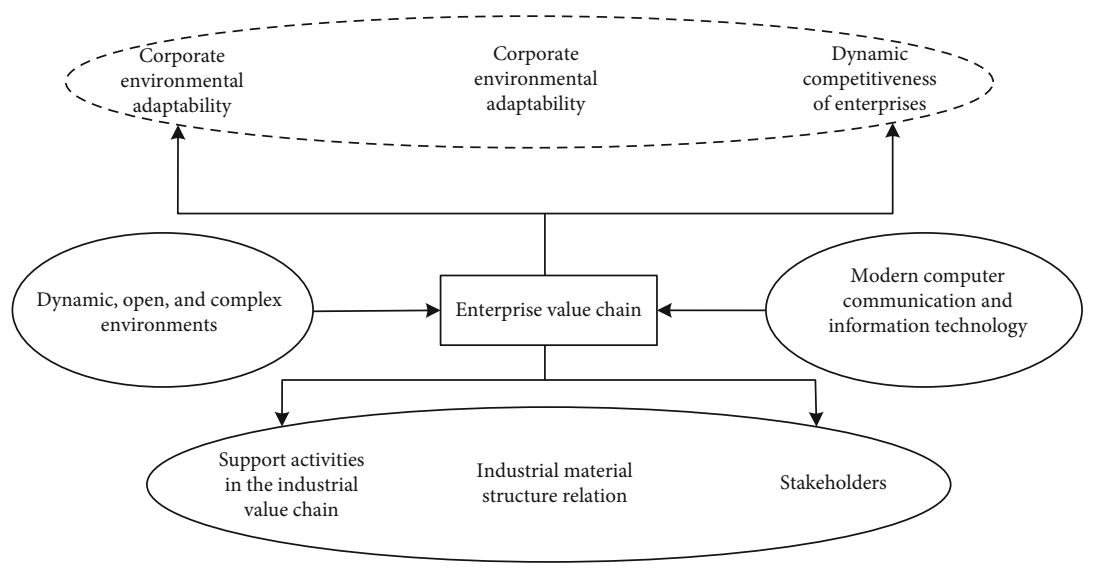

FIGURE 3: Industrial value chain structure.

In addition to value distribution and factor input, another important way for value chain to promote the virtuous cycle of resource chain and environment chain is the realization process of market transaction value. It is divided into two types of value chain links: resource chain and environment chain. Through the market mechanism, we can realize their value distribution of the economic system, make up for the lack of administrative measures and the unreasonable initial value distribution, and then use the system selforganization mechanism to realize the internal construction of the value chain.

The construction of an enterprise cost value chain system is to divide the enterprise into several value activities from the perspective of enterprise competitive advantage and then connect them organically. Through the analysis of the main value chain activities, we can achieve the competitive advantage of the enterprise and finally achieve the strategic goal of the enterprise. The structure of enterprise industrial value chain is shown in Figure 3.
An industrial value chain can be divided into raw material purchase cost value chain, production and processing cost value chain, and sales and after sales service cost value chain. In the actual operation process, it presents a dynamic state of change. Among them, raw material procurement refers to various activities related to product production, such as purchase, receiving, storage, and distribution [13]. The value chain of raw material purchase cost is formed. It consists of five value activities: purchase, transportation, handling, sorting, inventory, and inventory control.

2.2. Integration of Natural Resources and Acquisition of Environmental Pollution Indicators. After the analysis of the hybrid structure of the resource chain, environment chain, and value chain models, it is necessary to integrate the natural resources to lay the foundation for the construction of the model. The integration of natural resources is mainly the integration of raw materials and 
processing materials. The objective function of natural resource integration is as shown in

$$
F(x)=\operatorname{Max}\left(\sum B_{i} * V_{i}\right)
$$

In the formula, $B_{i}$ is the type and quantity of natural resources to be used in the production process of the enterprise and $V_{i}$ represents the quantity of natural resources of a single type to be used. According to the objective function, the raw materials needed for enterprise production are integrated, and the hybrid content of resources in the hybrid model of resources environment value chain is obtained.

The hybrid model of resource environment value chain is designed to realize the unification of environmental, economic, and social benefits. From the perspective of providing material products and services, there is no difference between the environment and general material production departments and service provision departments. In addition to the environmental industry, the production process of other material production departments is to obtain natural resources and turn them into means of life and means of production through processing natural resources. The purpose of production is to change the material form of the labor object, so as to meet the needs of human beings. When commodities enter the consumption domain, it marks the end of the production process [14]. Not only the production process needs to consume resources and energy, but also after the commodity enters the consumption process, it will continue to consume resources. After the commodity is consumed, it will enter the environment in the form of waste. The production process and consumption process show that people's unilateral demand for resources, reducing the stock of natural resources and reducing the capacity of environmental self-purification, cannot make economic benefits and environmental benefits unified. The connotation of environmental industry lies in the protection of natural resources, the rational use of resources, the treatment of environmental pollution, the removal of other material production departments, and consumers of environmental damage, and its production purpose highlights environmental benefits. Environmental change is mainly affected by human factors, among which the impact of enterprise production on the environment is the main factor leading to environmental change. Combined with the whole life cycle of enterprise products, the environmental cost measurement method is obtained, shown in

$$
T_{c}=M+C_{r}+C_{o}+C_{s}+C_{B}+C_{n}+C_{c o 2} .
$$

In the formula, $T_{c}$ represents the total environmental cost of the whole life cycle of the enterprise, $M$ represents the cost of resource depletion, $C_{r}$ represents the impact loss of resource consumption, $C_{o}$ represents the loss of air pollution, $C_{s}$ is the environmental loss caused by water pollution, $C_{B}$ is the pollution loss of solid waste, $C_{n}$ represents the loss of the impact of noise on the environment, and $C_{c o 2}$ is the loss of external environmental impact.
In the specific environmental cost measurement process, each environmental cost is measured. That is, the values of $M$ , $C_{r}, C_{o}, C_{s}, C_{B}, C_{n}$, and $C_{c o 2}$ are not fixed. According to the production projects of different enterprises, carry out specific calculation. Taking the resource consumption impact loss index as an example, the calculation formula of the index is as shown in

$$
C_{r}=\Delta L_{r} \times Q_{r}
$$

where $\Delta L_{r}$ is the unit resource consumption loss and $Q_{r}$ is the total loss of resource consumption. Similarly, it can be concluded that the calculation method of corresponding indicators of water pollution environmental loss is shown in

$$
C_{s}=V_{1}+V_{2}=Q_{s} \times f_{s}+\sum\left(\frac{Q_{1}}{Q_{0} \times p_{i}}\right)
$$

In the formula, $V_{1}$ and $V_{2}$ are the recovery cost and pollution discharge cost, respectively, $f_{s}$ is the unit governance cost, $Q_{s}$ and $Q_{0}$ are the sewage discharge, $Q_{1}$ is the emission amount and equivalent of a pollutant, and $p_{i}$ is the collection standard of each pollution equivalent. By using the same method, all environmental impact indicators can be obtained, so as to realize the analysis and rectification of environmental change characteristics.

2.3. Analysis of the Relationship between Resources, Environment, and Economic Value. Natural resources and environment are indispensable natural conditions for human survival and development and the basis of human activities. From the economic point of view, natural resources are a kind of multifunctional assets, which provide human with the shown four services:

(1) Provide human with natural resources. The natural environment provides natural resources for all kinds of economic activities of human beings, as the input of human production activities. Natural resources include all kinds of raw materials and energy needed by economic activities. Raw materials are transformed into consumer goods through the production process, and energy provides the necessary power for the production of commodities

(2) Provide public consumer goods for human beings. The natural environment provides public consumer goods for human beings, including free use of air, scenery, and people's leisure places

(3) Accept human waste. Human activities will produce a variety of wastes, which are discharged into people's environment. Some wastes are partially decomposed, collected, or transferred to other places. Waste discharge in the natural environment will become a pollutant through the diffusion process

(4) It provides space for human survival. The environment provides the location space of economic activities for the economic system, such as industrial land, 


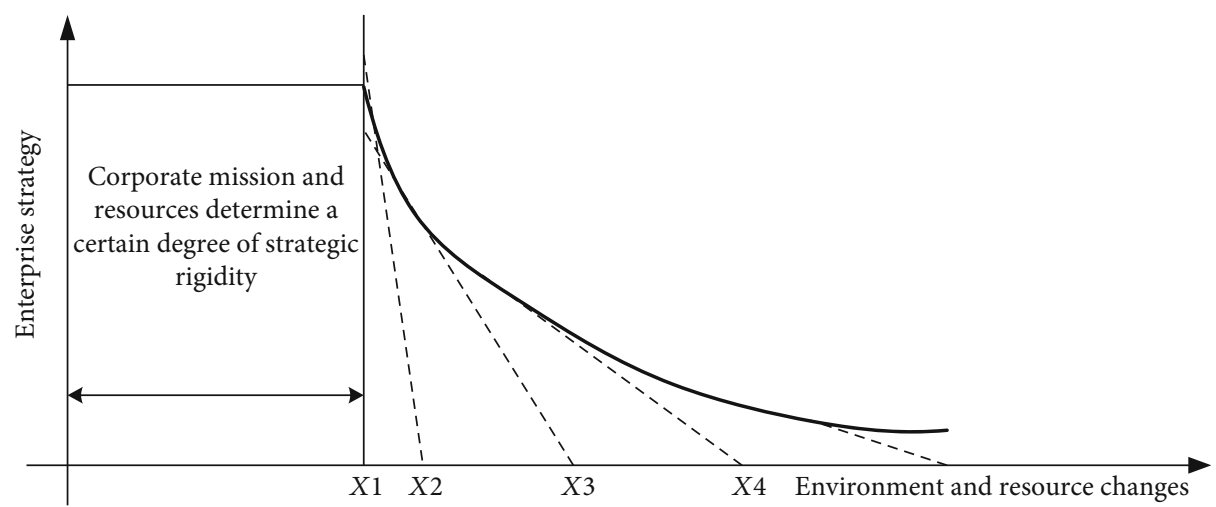

Figure 4: Development curve of enterprise economic value with the change of resources and environment.

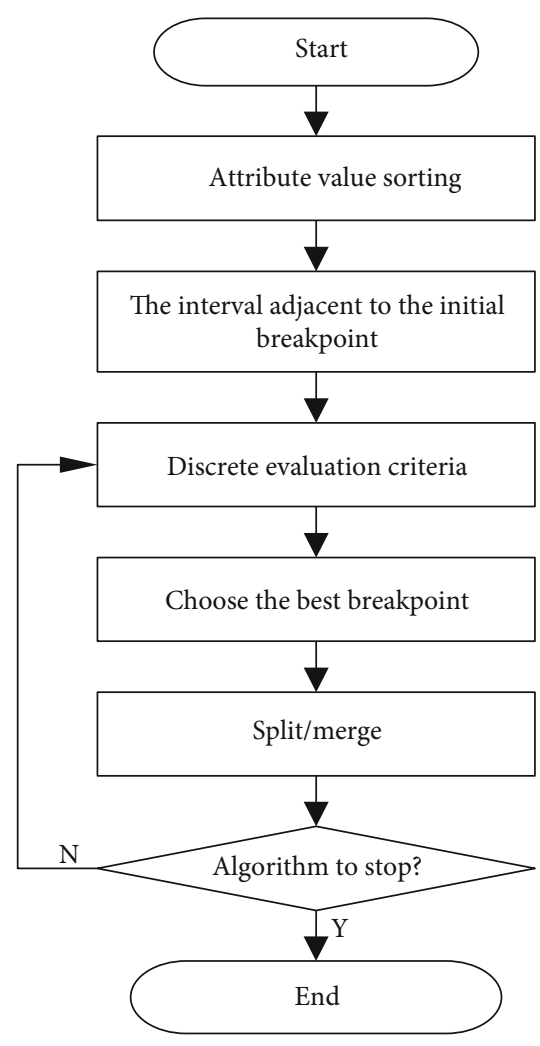

Figure 5: Flow chart of discrete time algorithm processing.

residential land, leisure land, agricultural land, and infrastructure land

A resource environment economy hybrid model is a complex model. Its complexity is mainly reflected in the diversity of model elements, the dynamics of model correlation, the dynamic existence of material circulation, energy flow, and information transmission and value-added in the model and between the model and environment. The relationship between enterprise economic value and resource environment is shown in Figure 4.

2.4. Content Determination of Industrial Value Chain. Production refers to the activities related to the transformation of inputs into final products. The resulting production cost value chain consists of six value activities: raw material handling, production products, finished product inspection, finished product handling, finished product abandonment, and finished product inventory. The cost accounting formula of the enterprise value chain at this stage can be expressed as shown in

$$
C_{z}=(M+W+R) *(1+r)+\frac{F}{Q} .
$$

In the formula, $M$ represents unit product material cost, $w$ represents unit product labor wage cost, $R$ represents unit product energy consumption expenditure, $R$ represents the proportion of general management cost of the enterprise, $F$ represents fixed asset depreciation, and $Q$ represents product output.

In the production process, in addition to the enterprise's own cost, the environment cost also needs to be calculated. The cost calculation formula is as shown in

$$
C_{h}=\frac{\left(C_{e 1}+C_{e 2}+C_{e 3}+C_{e 4}\right)}{Q} .
$$

The environmental cost is mainly divided into four parts: pollution emission control cost, waste disposal cost, ecological environment tax, and pollution penalty cost. The calculation method of each index is as shown in

$$
\left\{\begin{array}{l}
C_{e 1}=(F+Q) * C_{v}, \\
C_{e 2}=\text { Num } \times \text { Mon, } \\
C_{e 3}=Q^{\prime} \\
C_{e 4}=Y .
\end{array}\right.
$$

In the formula, $F$ and $C_{v}$ are the fixed cost and variable cost, respectively, Num and Mon are the standard unit prices of waste disposal volume and waste disposal charges, and $Q^{\prime}$ and $Y$ represent the standard unit price of environmental tax and pollution charge for regulating the behavior of damaging environment and resources.

Sales refers to various activities that guide customers to buy enterprise products and deliver them to their hands 
TABLE 1: Experimental parameters.

\begin{tabular}{|c|c|c|}
\hline Variable factors of & $\begin{array}{l}\text { Details of } \\
\text { variable }\end{array}$ & Description of measurement items \\
\hline \multirow{5}{*}{ Cost synergies } & $Y 1$ & $\begin{array}{l}\text { It helps enterprises in the circular economy industry chain to pursue the common goal of } \\
\text { cost reduction }\end{array}$ \\
\hline & $Y 2$ & It can improve the utilization of resources and reduce the cost of raw materials \\
\hline & $Y 3$ & It is helpful to reduce the cost of internal production and operation \\
\hline & Y4 & $\begin{array}{l}\text { It is helpful to reduce the environmental cost and improve the environmental management } \\
\text { efficiency and ecological efficiency }\end{array}$ \\
\hline & Y5 & $\begin{array}{c}\text { It helps to reduce the transaction cost between enterprises and improve the internal } \\
\text { operation efficiency }\end{array}$ \\
\hline \multirow{4}{*}{$\begin{array}{l}\text { Core enterprise internal } \\
\text { collaboration }\end{array}$} & $X 1$ & $\begin{array}{l}\text { The company's internal procurement, production, sales, and logistics departments to } \\
\text { participate in the product ecological design }\end{array}$ \\
\hline & $X 2$ & $\begin{array}{l}\text { R\&D designers should be familiar with cost control, environmental protection, and } \\
\text { resource recycling technologies }\end{array}$ \\
\hline & $X 3$ & $\begin{array}{c}\text { The whole process cost control should be implemented in the whole life cycle of the } \\
\text { product }\end{array}$ \\
\hline & $X 4$ & The production process of an enterprise shall implement cleaner production techniques \\
\hline \multirow{4}{*}{$\begin{array}{l}\text { Collaboration with profit and } \\
\text { waste enterprises }\end{array}$} & $X 5$ & Build the material circulation system with waste enterprises \\
\hline & $X 6$ & Share special equipment and other resources with waste enterprises \\
\hline & $X 7$ & Develop market and share marketing network in cooperation with waste enterprises \\
\hline & $X 8$ & To provide technical, production, and environmental support for waste enterprises \\
\hline
\end{tabular}

[15-17]. After sales service refers to the activities of providing services to increase or maintain the value of products after the sale of products. The resulting cost value chain of sales and after sales service consists of eight value activities: advertising, establishing distribution channels, order processing, commodity handling, commodity transportation, customer maintenance, customer training, and customer relationship management. Through the cost accounting of each environment of enterprise production and sales, the value and value chain analysis results of enterprise products are obtained, which are regarded as resource environment-value chain nesting content in the value chain nesting model.

\section{Hybrid Resource Environmental Value Chain Model Based on a Discrete Time Algorithm}

3.1. Model Continuous Attribute Analysis. The purpose of discretization of model continuous attributes is to transform three different types of data in the hybrid model, resources, environment, and value chain, into discrete form and individual data, so as to realize the transformation of three information formats. Through optimal synthesis, the coupling relationship among the three components of the model can be guaranteed. The processing flow of the discrete-time algorithm is shown in Figure 5.

The state of linear discrete time can be expressed as shown in

$$
x(k)=\varphi(k, k-1) x(k-1)+w(k-1) .
$$

In the formula, system noise $w(k)$ is a white noise sequence with zero mean. The random vector whose initial state $x(0)$ is mean $m(0)$ and variance matrix $\sum 0$ is defined. There arelobservation stations to evaluate the model independently as shown in

$$
z_{i}(k)=C_{i}(k) x(k)+v_{i}(k)
$$

In the formula, measurement noise is $v_{i}(k)$ white noise sequence with zero mean. In the centralized processing, all measurement data $z_{i}(j)$ are fed to the central processor, to obtain the optimal estimation of the linear minimum variance of the overall state $x(k)$, shown in

$$
\widehat{x}=(k \mid k)=\widehat{E}\left\{x(k) \mid z_{i}(j)\right\}
$$

In the formula, $E\{x i(k) \mid z i(j)\}$ is the orthogonal projection operator. In the decentralized processing, each local processor will provide local measurement data $\left\{z_{i}(j)\right\}$ according to its own observation station. According to Equation (10), the optimal estimation of the linear minimum variance of the local state $x_{i}(k)$ is obtained. Then, the discrete decomposition of the local model can be expressed as shown in

$$
C_{i}(k)=H_{i}\left(x_{i}(k)\right) \text {. }
$$

In the formula, $H()$ is a discrete-time processing function. The three hybrid contents of resources, environment, and value chain are, respectively, substituted into the above formula to realize the discretization of each module content. Using Equation (12) to achieve the optimal synthesis of 
discrete content, namely,

$$
\widehat{x}(k \mid k)=\xi(k)+\sum_{i=1}^{L} G_{i}(k) \widehat{x}_{i}(k \mid k) .
$$

In the formula, $G_{i}(k)$ is the corresponding expression of synthesizer and $\xi(k)$ represents three hybrid content states.

3.2. Resource Environment Economy Hybrid Model Implementation. On the basis of planning resource environment economy hybrid model structure, discrete data synthesis hybrid content will be processed, respectively. The hybrid operation of models is realized by the relationship among them. In the process of running the resource environment economy hybrid model, it is necessary to allocate the cost consumption reasonably, realize the collaborative matching of each module, and optimize the information scheduling between discrete time and cost balance [18-20]. From the two aspects of equilibrium index and nesting strength of hybrid models, the constraints of the model are set, shown in

$$
\left\{\begin{array}{l}
\text { GVCEVA_Balance Ratio }=\frac{\mathrm{EVA}_{k j}-\mathrm{EVA}_{j k}}{E_{j}+E_{k}}, \\
\text { GVCEVA_Link }=\frac{\mathrm{EVA}_{k j}+\mathrm{EVA}_{j k}}{E_{j}+E_{k}} .
\end{array}\right.
$$

In the formula, $\mathrm{EVA}_{j k}$ and $\mathrm{EVA}_{k j}$ are the values added between any two hybrid cells in the model. Set the parameter value and constraint threshold of constraint conditions in the model to realize the nesting of resource environment economy.

\section{Experimental Analysis}

4.1. Experimental Environment. In order to verify the comprehensive effectiveness of the design model, simulation experiments are carried out. The experiment is carried out on MATLAB 6.0, and SPSS 13.0 software is used for data processing.

4.2. Experimental Parameters. Because the hybrid model of resource environment value chain needs a certain period of time in the process of operation and the experiment period is long, in order to better carry out the experiment, the environmental data of a laboratory in the past three years is selected as the experimental sample data. There are 3000 pieces of economic information and current state data of resources and environment collected by the laboratory, including 1000 pieces of environmental pollution data, 1000 pieces of resource related data, and 1000 pieces of impact data after the realization of enterprise value. In order to verify the scientific validity of the design model, 3000 data were analyzed. The specific experimental parameters are shown in Table 1.

4.3. Experimental Scheme. The experiment adopts the method of comparison, comparing the model of this paper, the model of literature [4], and the model of literature [5]. The data

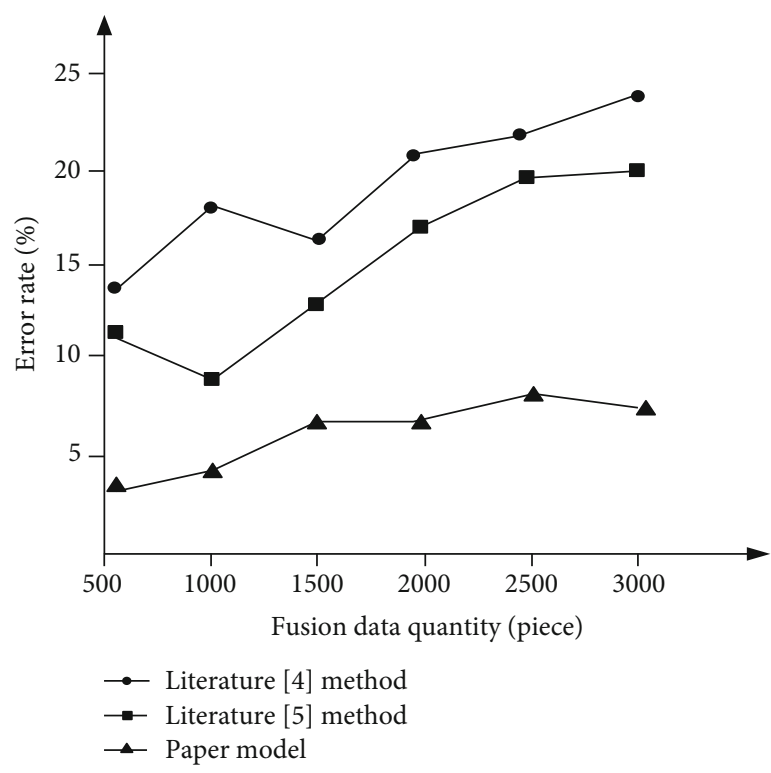

Figure 6: Comparison of data fusion errors of different models.

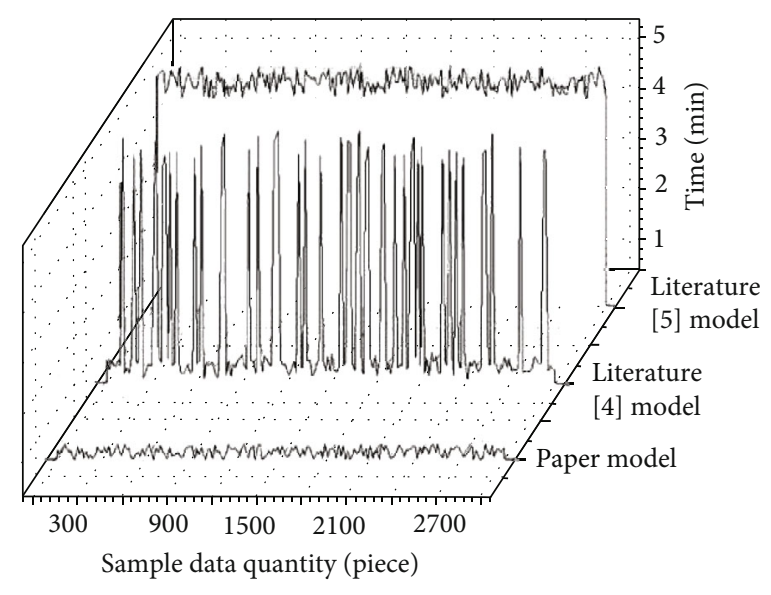

Figure 7: Comparison of evaluation time of different models.

TABLE 2: Comparison of resource saving rate of different models (\%).

\begin{tabular}{lccc}
\hline Iterations/time & $\begin{array}{c}\text { Paper } \\
\text { model }\end{array}$ & $\begin{array}{c}\text { Literature [4] } \\
\text { model }\end{array}$ & $\begin{array}{c}\text { Literature [5] } \\
\text { model }\end{array}$ \\
\hline 2 & 94 & 89 & 85 \\
4 & 95 & 85 & 86 \\
6 & 94 & 87 & 83 \\
8 & 96 & 82 & 80 \\
10 & 97 & 80 & 75 \\
\hline
\end{tabular}

fusion degree of the model, the time to complete the evaluation of the model, and the resource saving rate of the model are selected as the experimental indicators for verification.

\subsection{Analysis of Experimental Results}

4.4.1. Error Analysis of Data Fusion of Different Models. In order to verify the scientific validity of the proposed model, 


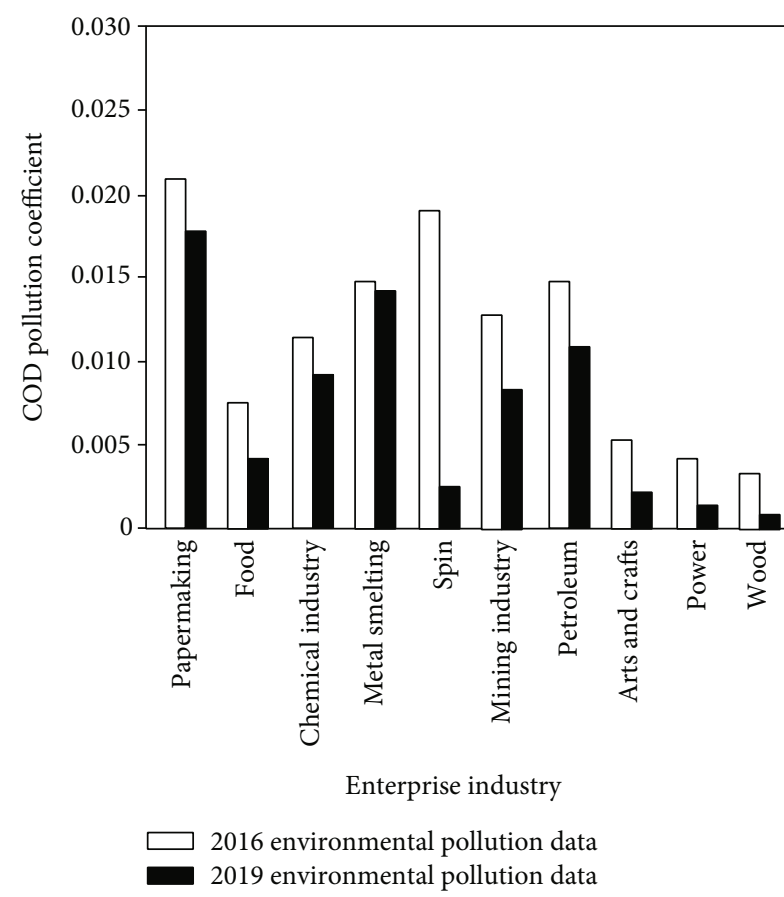

(a) Cod direct pollutant production coefficient

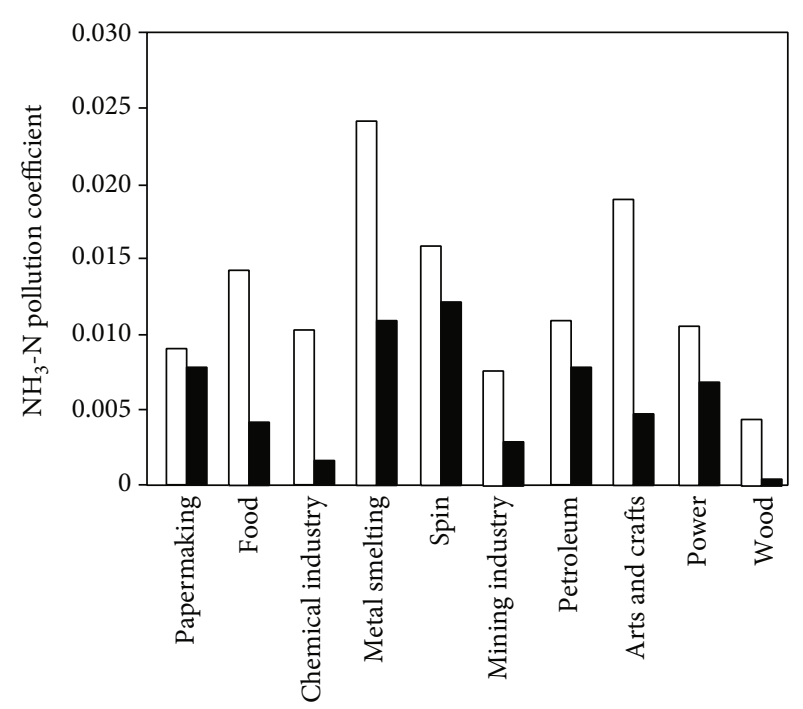

Enterprices industry

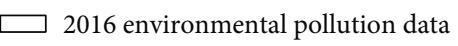

2019 environmental pollution data

(b) Direct pollutant production coefficient of ammonia nitrogen

Figure 8: (a, b) Comparison results of environmental protection functions [21].

the fusion errors of the model, document [4] model, and document [5] model to the data of resources, environment, and value chain are studied. Among them, the lower the error result, the better the fusion degree of the representative model to the data. The experimental results are shown in Figure 6.

From the analysis of Figure 6, it can be seen that there is a certain gap in the error of data fusion of resources, environment and value chain with three models under the same conditions. Among them, when the data volume is 1500 , the error rate of document [4] model fusion is about $15 \%$, the error rate of document [5] model fusion is about $13 \%$, and the error rate of this model fusion is about $7 \%$; when the data volume is 3000 , the error rate of document [4] model fusion is about $18 \%$, the error rate of document [5] model fusion is about $13 \%$, and the error rate of this model fusion is about $6 \%$. Compared with the other two models, the data fusion error of this model is increased by $7 \%$ and $12 \%$, respectively. This is because the proposed model analyzes the structure of resource, environment, and value chain data and integrates the natural resource data with discrete-time algorithm, which improves the accuracy of data fusion.

4.4.2. Time-Consuming Analysis of Different Models. In order to verify the scientific validity of the proposed method, the time consumption of resource, environment, and value chain data evaluation of this model, literature models $[4,5]$ are analyzed. Among them, the shortest time used indicates the faster processing speed. The experimental results are shown in Figure 7.

From the analysis of Figure 7, it can be seen that the time consumption of three methods for resource, environment, and value chain data evaluation is not the same. Among them, the evaluation time of this model is always less than $1 \mathrm{~min}$, the evaluation time of literature [4] model is about $2.9 \mathrm{~min}$, and the evaluation time of literature [5] model is about $4.2 \mathrm{~min}$. In contrast, the time consumption of this model is saved by $1.9 \mathrm{~min}$ and $3.2 \mathrm{~min}$, respectively, which verifies the feasibility of this model.

4.4.3. Analysis of Resource Savings in Different Models. In order to verify the comprehensive effectiveness of the model in this paper, the rate of three models is analyzed experimentally. The experimental results are shown in Table 2 .

According to the data in Table 2, the saving rate of environmental resources with three models is different. Among them, the resource saving rate of the model in this paper is up to $97 \%$, the resource saving rate of the model in literature [4] is up to $89 \%$, and the resource saving rate of the model in literature [5] is $86 \%$. In contrast, the resource saving rate of the model in this paper is the highest, which verifies the scientific effectiveness of the proposed method.

4.4.4. Environmental Protection Functions. The verification of the environmental protection function is to compare the environmental pollution around the enterprise before and after the application of the model. In this verification, the environmental pollution index sets for comparison are cod direct pollution production coefficient, ammonia nitrogen direct pollution production coefficient, $\mathrm{SO}_{2}$ direct pollution production coefficient, nitrogen oxide direct product coefficient, and smoke dust direct product coefficient. Among them, the comparison of COD direct pollution generation coefficient and ammonia nitrogen direct pollution generation coefficient is shown in Figure 8. 
From the analysis of Figure 8, it can be seen that after applying the hybrid model of resource environment value chain based on the discrete-time algorithm, both the COD direct pollution generation coefficient and the ammonia nitrogen direct pollution generation coefficient have decreased, and COD can be calculated quantitatively. The direct pollution coefficient is reduced by 0.0396 , while the direct ammonia nitrogen pollution coefficient is reduced by 0.065 . Through the calculation of all environmental pollution coefficients, it can be found that the hybrid resource environment value chain model can be applied to the operation of the enterprise, which can control the enterprise value and reduce the environmental pollution degree of the product production to a certain extent, so as to realize the environmental protection.

\section{Conclusions}

The circulation of resource chain, ecological chain, and value chain is not completed independently; they are intertwined and promote each other, so this paper proposes a hybrid resource environmental value chain model based on a discrete time algorithm. By analyzing the structure of resource chain, ecological chain, and value chain, the interaction among resource chain, ecological chain, and value chain is obtained. Based on the traditional hybrid model, the discrete-time algorithm is introduced to construct the hybrid model of resource environment value chain. Its overall structure model can make clear the relationship between complex natural environment and value, facilitate the development of ideas in the process of enterprise economic construction, and facilitate the scientific formulation of national and regional circular economy strategic planning. The experiment is carried out on MATLAB 6.0. According to the simulation results, the error rate of the proposed model fusion is about $6 \%$. Compared with the other two models, the data fusion error of the proposed model is increased by $7 \%$ and $12 \%$, respectively. With respect to time-consuming analysis, the evaluation time of proposed model is always less than $1 \mathrm{~min}$ compared to the other two existing models. The saving rate of environmental resources with three models is different. Among them, the resource saving rate of the proposed model is up to $97 \%$, and those of the remaining two models are up to $89 \%$ and $86 \%$. It proved that the resource saving rate of the model in this paper is the highest. Finally, it can be found that the hybrid resource environment for the COD pollution is reduced by 0.0396 and the $\mathrm{NH} 3-\mathrm{N}$ pollution is reduced by 0.065 .

This model is conducive to the decision-making bodies such as the relevant industry associations of production enterprises and the relevant management departments of governments at all levels. When making the decision of different levels of enterprises, according to their different requirements and concerns, it is not only able to get what they need but also easy to understand the relationship between the local structure and the overall system and also conducive to coordinating the interaction of various stakeholders.

\section{Data Availability}

Data are available on request.

\section{Conflicts of Interest}

The authors declare no conflicts of interest.

\section{References}

[1] M. Chen, M. Fan, C. B. Xie, A. L. Peace, and H. Wang, "Stoichiometric food chain model on discrete time scale," Mathematical Biosciences \& Engineering Mbe, vol. 16, no. 1, pp. 101-118, 2019.

[2] J. H. S. Chong, Y. K. Wan, and V. Andiappan, "Synthesis of a sustainable sago-based value chain via fuzzy optimisation approach," in MATEC Web of Conferences, vol. 152, p. 01004, Selango, Malaysia, 2018.

[3] Y. H. Qu, A. N. Wang, and S. Lin, "A novel stable value iteration-based approximate dynamic programming algorithm for discrete-time nonlinear systems," Chinese Physics B, vol. 27, no. 1, pp. 010203-010203, 2018.

[4] Y. F. Liu and Y. W. Wang, "Analysis of market operation of enterprise annuity from the perspective of value chain," West Forum on Economy and Management (Journal of Sichuan Economic Management Institute), vol. 30, no. 4, pp. 71-80, 2019.

[5] R. Huang, H. Q. Zhang, and D. X. Chang, "A backup and recovery mechanism for security service chain fault in network function virtualization environment," Journal of Computer Research \& Development, vol. 55, no. 4, pp. 768-781, 2018.

[6] X. Xu, H. Chen, C. Q. Lian, and D. Z. Li, "Learning-based predictive control for discrete-time nonlinear systems with stochastic disturbances," IEEE Transactions on Neural Networks \& Learning Systems, vol. 29, no. 12, pp. 6202-6213, 2018.

[7] C. Y. Zhang, J. B. Li, and S. S. Wang, "Encrypted image retrieval algorithm based on discrete wavelet transform and perceptual hash," Journal of Computer Applications, vol. 38, no. 2, pp. 539-544, 2018.

[8] Z. Dai, H. Zhou, and F. Wen, "Efficient predictability of stock return volatility: the role of stock market implied volatility," North American Journal of Economics and Finance, vol. 52, p. 101174, 2020.

[9] K. U. Shang-qi, Z. H. Chao, L. I. Shuo, Y. A. Hai-gui, H. U. Tong-lin, and Z. H. Hong-jun, "Design and fabrication of broadband discrete extreme-ultraviolet multilayer based on quantum state genetic algorithm," Acta Photonica Sinica, vol. 47, no. 4, article 431001, 2018.

[10] Q. Jiao and D. Xu, "A discrete bat algorithm for disassembly sequence planning," Journal of Shanghai Jiaotong University, vol. 23, no. 2, pp. 276-285, 2018.

[11] Z. C. Zhang, W. Han, and B. Mao, "Adaptive discrete cuckoo algorithm based on simulated annealing for solving TSP," Acta Electronica Sinica, vol. 46, no. 8, pp. 1849-1857, 2018.

[12] F. H. Wen, Y. P. Zhao, M. Z. Zhang, and C. Y. Hu, "Forecasting realized volatility of crude oil futures with equity market uncertainty," Applied Economics, vol. 51, no. 59, pp. 64116427, 2019.

[13] Q. Sun, X. H. Zhang, H. W. Zhang, and H. P. Niu, "Coordinated development of a coupled social economy and resource environment system: a case study in Henan Province," China, Environment Development \& Sustainability, vol. 20, no. 1, pp. 1-20, 2018. 
[14] E. K. Rousham, L. Unicomb, and M. A. Islam, "Human, animal and environmental contributors to antibiotic resistance in low-resource settings: integrating behavioral," Proceedings of the Royal Society B: Biological Sciences, vol. 285, no. 1876, article 20180332, 2018.

[15] G. X. Xiao, B. Yang, and W. Li, "Big data resource planning for food safety: a preliminary exploration of the "environment, food and health" information chain," Journal of Resources and Ecology, vol. 9, no. 1, pp. 22-27, 2018.

[16] C. Yan and M. Lin, "Coordination of the "economy-societyenvironment" triad in the transition development of resource: based cities in Northeast China," Geographical Research, vol. 37, no. 2, pp. 307-318, 2018.

[17] A. J. Benjamin and S. M. McDermott, "Health impacts of invasive species through an altered natural environment: assessing air pollution sinks as a causal pathway," Environmental \& Resource Economics, vol. 71, no. 1, pp. 23-43, 2018.

[18] D. Howard, A. F. R. T. Mirjam, and D. Mercy, "Advanced value chain collaboration in Ghana's cocoa sector: an entry point for integrated landscape approaches," Environmental Management, vol. 62, no. 1, pp. 143-156, 2018.

[19] Y. S. Chen and L. L. Wang, "Simulation of multi-source information resource fully homomorphic encryption under cloud computing environment," Computer Simulation, vol. 35, no. 7, pp. 117-120, 2018.

[20] B. W. William and A. E. Edward, "Welfare impact of wheat farmers participation in the value chain in Tanzania," Modern Economy, vol. 9, no. 4, pp. 853-887, 2018.

[21] A. Miszkowska, A. Sieczka, and E. Koda, "Levels of organic pollution indicators in groundwater at the old landfill and waste management sit," Applied Science, vol. 7, no. 638, pp. 1-22, 2017. 